\title{
CICLO HIDROLÓGICO PLANETÁRIO: abordagens e Conceitos
}

\author{
Ricardo Augusto Calheiros de MIRANDA ${ }^{1}$ \\ Marcus Vinicius Siqueira de OLIVEIRA ${ }^{2}$ \\ Danielle Ferreira da SILVA ${ }^{3}$
}

\begin{abstract}
RESUMO
Este artigo oferece uma discussão conceitual a respeito dos componentes do Ciclo Hidrológico. Ele apresenta definições de cada um dos seus componentes aceitos cientificamente na bibliografia nacional e internacional. Apresenta noções construídas coletivamente por diferentes autores em seus estudos e pesquisas relacionadas sobre o tema.

Ao final, os autores consideram que a definição mais adequada é formada por uma fusão das noções discutidas e apresentadas regularmente, em que se une a percepção das pessoas com os conceitos já estabelecidos na literatura. Assim abre-se espaço para aplicar e adaptar os conceitos apresentados conforme as pesquisas e/ou objetivos pedagógicos de cada atividade e de acordo com a área estudada.
\end{abstract}

Palavras-Chaves: Ciclo Hidrológico, Geografia Física, Climatologia

\begin{abstract}
This article offers a conceptual discussion regarding the components of the Hydrological Cycle. It provides definitions of each of its components scientifically accepted in international and national literature. Presents concepts collectively constructed by different authors in their studies and research related on the topic.

At the end, the authors consider the most appropriate definition is formed by a merger of the concepts presented and discussed regularly, where it joins the perception of people with the concepts already established in the literature. So there is room to apply and adapt the concepts presented according to the research and / or educational objectives of each activity, according to the study area.
\end{abstract}

Key Words: Hydrologic Cycle, Physical Geography, Climatology

A quantidade total de água existente na Terra, nas suas três fases, sólida, líquida e gasosa, se tem mantido constante, desde o aparecimento do Homem. Distribuem-se por três reservatórios principais, os oceanos, os continentes e a atmosfera, entre os quais existe uma circulação contínua - Ciclo Hidrológico (PINTO et. al., 1979; WARD e ROBINSON, 2000; LIMA, 2008). Nas formas líquidas e sólidas a água cobre mais de 2/3 da superfície terrestre, e na forma gasosa é constituinte variável da atmosfera (podendo ocupar até $4 \%$ de todo seu volume). Sob tais condições, o vapor de água,

\footnotetext{
${ }^{1}$ Instituto de Geografia - Departamento de Geografia Física - Universidade do Estado do Rio de Janeiro - UERJ.

${ }^{2}$ Bolsista CETREINA - Departamento de Geografia Física - Instituto de Geografia - Universidade do Estado do Rio de Janeiro - UERJ.

${ }^{3}$ Bolsista Voluntária - Departamento de Geografia Física - Instituto de Geografia - Universidade do Estado do Rio de Janeiro - UERJ.
} 
ocorrendo se concentra em maior quantidade nas regiões tropicais e nas camadas mais baixas da atmosfera (CAMARGO, 2005).

A água é, portanto, constituída de moléculas que se atraem pela força de coesão. Essas moléculas no estado líquido estão em constante movimentação, movendo-se verticalmente no sentido da atmosfera terrestre e horizontalmente no sentido da superfície terrestre. Essa agitação molecular é proporcional à energia ou à temperatura da água. Se a temperatura aumentar, as moléculas mais agitadas da superfície tendem a escapar da massa líquida e ficar livres na atmosfera, em estado gasoso. Se a temperatura da água líquida diminuir, a movimentação das moléculas também diminui. Se chegar a zero grau centígrado, as moléculas serão fixadas e a água solidificará, formando o gelo.

Assim o Ciclo Hidrológico se constitui de uma sucessão de vários processos na natureza pelos quais a água inicia o seu caminho indo de um estágio inicial até retornar a posição primitiva. Este fenômeno global de circulação fechada da água entre a superfície terrestre e a atmosfera, é impulsionado fundamentalmente pela energia radiante e associado à gravidade e à rotação terrestre. Estima-se que cerca de $10 \%$ do total de vapor seja reciclado diariamente.

A superfície terrestre abrange os continentes e os oceanos, participando do ciclo hidrológico a camada porosa que recobre os continentes (solos, rochas) e o reservatório formado pelos lagos, rios e oceanos. Parte do ciclo hidrológico é constituída pela circulação da água na própria superfície terrestre, isto é; a circulação de água no interior e na superfície dos solos e rochas, nos lagos e demais superfícies líquidas e nos seres vivos (animais e vegetais).

O intercâmbio entre as circulações da superfície terrestre e da atmosfera ocorre em dois sentidos:

a) No sentido superfície-atmosfera, onde o fluxo de água ocorre fundamentalmente na forma de evaporação das águas oceânicas e evapotranspiração continental;

b) No sentido atmosfera-superfície, onde a transferência ocorre em qualquer estado físico, sendo mais significativas, em termos globais, as precipitações pluviométricas, o granizo e a neve (Figura 1): 


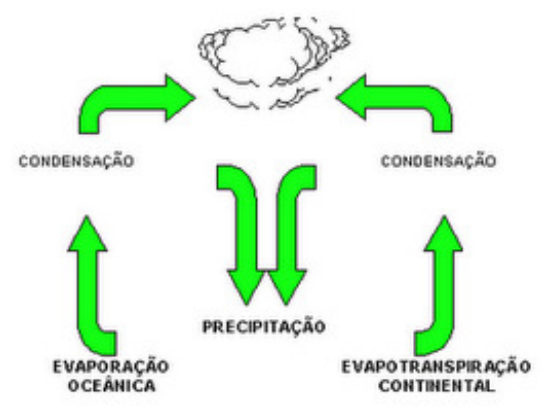

Figura 1 - Representação do ciclo hidrológico

O ciclo hidrológico na superfície terrestre pode ser descrito por sete processos distintos, ou seja:

\section{EVAPOTRANSPIRAÇÃO}

$\mathrm{Na}$ natureza ao conjunto de fenômenos que transformam em vapor a água precipitada sobre as superfícies continentais e sobre a dos mares, dos lagos, dos rios e dos reservatórios, denomina-se evaporação. Muito embora o vapor de água possa ser formado diretamente, a partir da sublimação das geleiras, o interesse climatológico está mais concentrado nas mudanças de fase do líquido para o vapor.

- Evaporação - conjunto de fenômenos físicos que condicionam a transformação da água na forma líquida ou sólida, de uma superfície úmida ou de água livre, em vapor, devido à radiação solar e aos processos de difusão molecular e turbulenta. Além da radiação solar, outros elementos meteorológicos tais como: temperatura do ar, vento e pressão de vapor, também interferem na evaporação principalmente em superfícies líquidas.

- Transpiração - Perda de água para a atmosfera na forma de vapor através dos estômatos e cutículas das plantas, decorrente das ações físicas e fisiológicas dos vegetais, e dependentes da disponibilidade de energia da água disponível no solo e governada pela resistência dos estômatos.

Este processo global de circulação fechada e perpétua da água entre a superfície terrestre e a atmosfera, é impulsionado pela energia radiante, forças do vento e associado às forças da gravidade terrestre.

$\mathrm{Na}$ natureza o solo, as plantas e a atmosfera podem ser consideradas como componentes de um sistema fisicamente inter-relacionado e dinâmico, no qual processos de fluxo estão interligados como elos de uma corrente (REICHARDT, 1990). Neste sistema, é importante e aplicável o conceito de potencial hídrico, ou seja, o fluxo 
de água se move dos locais de maior potencial para os de menor potencial. Ou seja, o fluxo sempre se dirige em direção do gradiente de potencial negativo.

A quantidade de água transpirada diariamente é grande em relação às trocas de água na planta, de modo que se pode considerar o fluxo através da planta, em curtos períodos de tempo, como um processo em regime permanente. As diferenças de potencial, em distintos pontos dentro do ecossistema são proporcionais à resistência do fluxo. A menor resistência ao fluxo é encontrada na planta. E a maior resistência é detectada, no fluxo das folhas para atmosfera, devido à mudança do estado líquido para o vapor. A passagem para atmosfera ocorre através dos estômatos localizados nas folhas. O transporte de água desde as folhas até o ar atmosférico ocorre também por difusão de vapor, sendo o mesmo proporcional a tensão do vapor de água. A umidade relativa do ar, ou seja, a relação entre a tensão real e a de saturação de vapor, relacionase exponencialmente com o potencial hídrico da planta (REICHARDT, 1990).

Assim a evaporação e a transpiração representam uma fração significativa do movimento da água através do Ciclo Hidrológico. Dentro de um contexto de uma pesquisa hidrológica, se comparados com o escoamento superficial, a evaporação e a transpiração não são variáveis muito importantes. Todavia, em se tratando de outro tipo de estudo a evaporação passa a fazer parte da equação das perdas, representando uma pequena fração das perdas durante as precipitações. Embora alcance, em projetos de grandes reservatórios, um processo de grande relevância.

Diante do exposto, a Evapotranspiração é definida pelo conjunto de processos físicos (evaporação) e fisiológicos (transpiração) responsáveis pela transformação em vapor atmosférico a água precipitada na superfície terrestre (TUCCI e BELTRAME, 2000). Todavia, a transferência da água de ecossistemas naturais (floresta, área cultivada), onde o teor de umidade do solo não é limitante, ocorre devido à intensidade do potencial hídrico e as diferenças de padrões meteorológicos prevalecentes no local e/ou região (REICHARDT, 1990; TUCCI, 2000).

Assim sendo o principal parceiro no ciclo hidrológico da evapotranspiração, passa a ser as diferentes formas como as águas se precipitam sobre a superfície terrestre. Ou seja, as precipitações consideradas como elementos alimentadores da fase terrestre do ciclo hidrológico e constituindo-se de importante fator para os processos de escoamento superficial direto, infiltração, evaporação, transpiração, recarga de aqüíferos 
e vazão básica dos rios. Ou seja, cerca de $70 \%$ da quantidade de água precipitada sobre a superfície terrestre retorna atmosfera via evaporação e transpiração.

Por essa razão as chuvas representam, no ciclo hidrológico, importante papel de elo entre os fenômenos meteorológicos, propriamente ditos, e os demais componentes do ciclo hidrológico (TUCCI, 1997).

\section{PRECIPITAÇÃO}

$\mathrm{Na}$ Terra a evapotranspiração representa a transferência da água da superfície continental e oceânica para atmosfera, ou seja, a passagem da água do estado líquido para o gasoso. Na atmosfera essa água se condensa, formando nuvens, que se precipitam na direção da superfície terrestre - formando um processo inverso à evapotranspiração. Ou seja, o retorno da água retida na atmosfera, através da chuva, neve e o granizo.

Assim sendo a precipitação é definida em Climatologia como sendo toda água proveniente do meio atmosférico que atinge a superfície terrestre na forma de chuva, neve e granizo.

\section{CHUVA}

Conjunto de águas originárias do vapor de água atmosférico que se precipitam, em estado líquido sobre a superfície terrestre em consequiência da intensificação da evapotranspiração sobre superfícies quentes e úmidas.

A formação das chuvas está associada à ascensão das massas de ar quente e úmidas e a formação de nuvens. As nuvens se formam pela perda do ar conter umidade. Isto ocorre normalmente, quando massas de ar que estão com alta umidade relativa, sofrem resfriamento.

$\mathrm{Na}$ atmosfera ascensão do ar quente e úmido provoca um resfriamento do ar que pode fazê-lo atingir o seu ponto de saturação, ou seja, sua capacidade de conter umidade. Ao atingir a $100 \%$ da sua capacidade, se seguirá a condensação do vapor de água em forma de minúsculas gotas que são mantidas em suspensão, como nuvens ou nevoeiros. 
Para ocorrer uma chuva é necessário que essas gotículas cresçam a partir de "núcleos de condensação" (poeira, aerossóis e etc.) até atingirem um peso suficiente capaz de sobrepor as forças de sustentação e, portanto se precipitarem.

São três os tipos de chuvas na Natureza:

- Chuvas Convectivas - Provocadas por diferenças de locais de aquecimento nas camadas atmosféricas. São chuvas formadas pela ascensão das massas de ar quente da superfície, carregadas de vapor d'água. Ao subir o ar sofre resfriamento provocando a condensação do vapor de água presente e, consequientemente, a precipitação. São características deste tipo de precipitação as chuvas de curta duração, alta intensidade, trovoadas, rajadas de ventos e pela sua abrangência em pequenas áreas;

- Chuvas Orográficas - são chuvas que são oriundas da passagem de uma massa de ar quente e úmido por uma cadeia de montanha, provocando a ascensão forçada do ar, que gradativamente se esfria provocando a condensação do vapor de água e conseqüentemente a formação de nuvens que se precipitam. Caracterizam-se pela sua longa duração e baixa intensidade e por não apresentarem qualquer tipo de descarga elétrica;

- Chuvas Frontais - são originárias do deslocamento de frentes frias ou quentes contra frentes contrárias termicamente. Ou seja, são chuvas que ocorrem ao longo da linha de descontinuidade, separando uma massa de ar de características diferentes. Ou seja, quando uma massa de ar quente e úmida, estacionária, ou oriunda do quadrante norte encontra com uma massa de ar frio, oriunda do quadrante sul. A frente fria, mais densa, entra por baixo, levando para cima a massa de ar quente. Quando esta massa de ar quente possui elevada umidade relativa, a chuva é iminente. É uma chuva de menor intensidade, com pingos menores, e de longa duração. É uma chuva de menor intensidade, com pingos menores, e de longa duração. Ocorre por vários dias, apresentando pausas e chuviscos entre fases mais intensas. Na metade sudeste do continente, ocorrer em qualquer época do ano, mas tem maior duração nos meses frios, quando os fenômenos atmosféricos são menos intensos. Pode produzir ventos fortes e grande quantidade de raios. Ocorre em uma imensa área simultaneamente.

\section{INTERCEPTAÇÃO DAS PRECIPITAÇÕES}

A superfície terrestre se constitui, em macro escala, obviamente, dos continentes e dos oceanos. Muito embora a menor parte do ciclo hidrológico seja constituída pela circulação da água nas superfícies continentais, isto é: a circulação de água no interior e na superfície dos solos e rochas, nos lagos e rios e principalmente no interior dos ecossistemas naturais (LIMA e LEOPOLDO, 2000; MIRANDA, 2006; RUTTER, 1975 e ZINKE, 1967). 
Num ecossistema, a fonte da entrada de água no solo é composta de precipitação pluviométrica menos a parcela dessa água que é gradativamente interceptada pela vegetação até que, pela saturação do dossel, essa água é então redistribuída por percolação direta pela copa e escoamento superficial ao longo do tronco. Já que é através da interceptação vegetal que, uma importante parcela das chuvas que atingem os ecossistemas naturais retorna à atmosfera por evaporação sem atingir ao solo, afetando a dinâmica do escoamento superficial e o processo de infiltração. Desse modo a vegetação exerce um importante papel no ciclo hidrológico tanto no nível de quantidade como de qualidade de água não somente pela evapotranspiração, mas também pela interceptação da água de chuva.

Interceptação é climatologicamente, definida como sendo a capacidade que a vegetação ou outro tipo de obstáculo possuem de reter a chuva nas suas copas. É um processo fortemente dependente das características das precipitações, das condições climáticas, da densidade da vegetação, da estrutura e arquitetura do dossel e do comportamento fisiológico das plantas durante o ano (TUCCI, 2000). Cabe-nos ressaltar que, em geral, uma folha não é capaz de absorver quase nada da água interceptada em sua superfície. Que a capacidade individual de retenção foliar é correlacionada com o tamanho da folha, com sua forma e com a viscosidade da água (RUTTER, 1975). Ressaltando-se as pressões externas causadas por ação dos ventos, do tipo e freqüência das precipitações dentre outras também influenciam no teor de água retida na vegetação.

\section{INFILTRAÇÃO}

Uma gota de chuva pode ser interceptada pela vegetação ou mesmo cair diretamente sobre o solo. Todavia a água ao atingir o solo poderá evaporar, penetrar no solo ou escoar superficialmente. A quantidade evaporada durante as chuvas intensas é desprezível em relação ao total precipitado. No entanto a água ao penetrar no solo reabastece os aquiferos subterrâneos que dependem as vazões dos cursos de água nos períodos de estiagem.

A Infiltração é, portanto, o processo de penetração da água nas camadas de solo próximas à superfície do terreno, movendo-se para baixo, através de vazios, sob a ação 
da gravidade, até atingir uma camada suporte que a retém, formando então o teor de umidade de um solo. Por essa razão torna-se uma das etapas mais importantes no ciclo hidrológico, uma vez que é responsável pela recarga de aqüíferos e influencia diretamente o escoamento superficial e, conseqüentemente a erosão hídrica (TUCCI e BELTRAME, 2000).

Usualmente, a infiltração decorrente de precipitações naturais não é capaz de saturar todo o solo, restringindo-se a saturar, quando consegue, apenas as camadas próximas à superfície, conformando um perfil típico onde o teor de água disponível decresce com a profundidade. Assim sendo, o padrão de distribuição da água em um solo uniforme, submetido a uma pequena carga hidráulica na superfície se divide por quatro zonas:

- Saturação - camada estreita (com espessura de $\approx 1,5 \mathrm{~cm}$ ) localizada logo abaixo do solo saturado;

- Transição - camadas caracterizadas pelo decréscimo acentuado da umidade com uma espessura em torno de $5 \mathrm{~cm}$;

- Transmissão - é a região do solo na qual a água é transmitida. Tem uma espessura flexível e associada às disponibilidades hídricas do solo.Ou seja, enquanto todas as zonas permanecem com espessura praticamente constante, esta aumenta a medida que há aplicação de água;

- Umedecimento - é uma região caracterizada por uma camada usualmente pequena, mas com grande redução de umidade com o aumento da profundidade.

Em suma, a infiltração da água em um solo depende:

- Umidade do solo - quanto mais saturado estiver o solo, menor será a infiltração;

- Tipo do solo - a granulometria do solo condiciona a sua permeabilidade. Quanto mais fino for o solo menor será a infiltração;

- Ocupação da superfície - os processos de urbanização e devastação da vegetação diminuem drasticamente a quantidade de água infiltrada ocorrendo o contrário com a aplicação de técnicas adequadas de terraceamento e manejo do solo;

- Topografia - declives acentuados favorecem o escoamento superficial direto diminuindo a oportunidade de infiltração;

- Depressões - a existência de depressões provoca a retenção da água diminuindo a quantidade de escoamento superficial direto. A água retida infiltra no solo ou evapora.

\section{ARMAZENAMENTO DA ÁGUA NO SOLO}


Redistribuição de água no solo é o movimento da água no perfil do solo depois de cessada a infiltração. Assim sendo a Capacidade de Campo, é, usualmente, definida como sendo a água retida pelo solo a partir do instante que em que a infiltração se torna desprezível. Ou seja, o limite superior de água que um determinado solo pode reter.

\section{ESCOAMENTO SUPERFÍCIAL}

O Escoamento Superficial (Runoff) é a fase do ciclo hidrológico que trata da água oriunda das precipitações que, por efeito da gravidade, se desloca sobre a superfície terrestre. Engloba, portanto, o volume de água precipitada sobre o solo saturado ou uma superfície impermeável que escoa superficialmente, seguindo linhas de maior declive, na direção de um curso de água mais próximo indo, posteriormente se desembocar nos oceanos. Sua duração está associada praticamente à duração da precipitação (TUCCI, 2000).

As águas precipitadas que atingem o leito do curso de água de um rio por 4 vias diversas:

- Escoamento Superficial- iniciado a partir da precipitação após a ação da interceptação pelos vegetais e/ou obstáculos, da saturação do solo e da subseqüente acumulação da água nas depressões do terreno;

- Escoamento Sub-Superficial - ocorre nas camadas superiores do solo, é difícil de ser separado do escoamento superficial;

- Escoamento Subterrâneo - oriundo do acumulo de água em aquíferos, é responsável pela alimentação do curso de água durante períodos de estiagem;

- Ação Direta das Precipitações - consequiência das águas que se precipitam sobre as superfícies líquidas.

\section{CONSIDERAÇÕES FINAIS}

Em princípio, o texto ora apresentado destina-se a estudantes e/ou profissionais da área de Geografia. No entanto, espera-se que o mesmo sirva, também, de referência para estudantes e/ou profissionais de áreas correlatas como meteorologia, ecologia, engenharia ambiental, gestão de recursos hídricos, entre outras.

Assim sendo o ciclo hidrológico quanto a sua ocorrência, transformações de estado e relações com a vida cotidiana é caracterizado pelas suas duas fases distintas, uma atmosférica e outra terrestre. Ou seja, em se considerando que água faz parte tanto do meio biótico (plantas, animais, microorganismos) e abiótico (atmosfera, solo), sendo 
encontrada na natureza nas três fases (sólida; líquida e gasosa). A ausência ou presença da água afeta o balanço de energia terrestre. Por essa razão, quando o conceito de ciclo hidrológico é aplicado em escala planetária, o volume de água disponível em cada parte do ciclo hidrológico é relativamente constante; porém, quando se considera uma área limitada, as quantidades de água em cada parte do ciclo variam continuamente, dentro de amplos limites. Assim se explica a abundância e a escassez das chuvas sobre o globo terrestre. 


\section{REFERÊNCIAS BIBLIOGRÁFICAS}

Camargo, A.P. A água no solo para agricultura. O Agronômico. Campinas. São Paulo. V. 57 (1). p. 10-11p. 2005.

Lima, P.R. A.; Leopoldo, P.L. Quantificação de componentes hidrológica de uma mata ciliar, através do modelo de balanço de massas. Revista Árvore, Viçosa, v.24, n.3, p. $241-252.2000$

Miranda, R.A.C. A interceptação das chuvas por ecossistemas. Agronline. 2006. (htpp://www.agronline.com.br/artigos/artigo.php?id+336)

Pinto, L. de S. N.; Holtz, A.C.T. e Martins, J.A. Hidrologia de Superfície. Editora Edgard Blücher. $2^{\circ}$ Edição. São Paulo. 1973. 179p.

Reichardt, K. A água em sistemas agrícolas. Editora Manole Ltda. São Paulo. 1990. $188 \mathrm{p}$.

Rutter, A.J., The hydrological cycle in vegetation. In J.L. Monteith (ed.), Vegetation and the Atmosphere, vol. 1- Principles, Academic Press, London, p. 111-154. 1975.

Silveira, A.L.; Louzada, J.A. e Beltrame, L.F. Infiltração e armazenamento no solo: In: Tucci, C.E.M. Hidrologia: ciência e aplicação, $2^{a}$ Ed., Porto Alegre. Rio Grande do Sul (RS). Editora Universidade, p.335-372, 2000.

Tucci, C.E.M. Hidrologia: ciência e aplicação. $2^{\text {a }}$ Ed., Porto Alegre. Rio Grande do Sul (RS). Editora Universidade. 2000. 943p.

Tucci, C.E.M. e Beltrame, L.F. Infiltração e armazenamento no solo: In: Tucci, C.E.M. Hidrologia: ciência e aplicação, $2^{\mathrm{a}}$ Ed., Porto Alegre. Rio Grande do Sul (RS). Editora Universidade, p.335-372, 2000.

Ward, R.C., Robinson, M., Principles of Hydrology. 4 Ed., McGraw-Hill, Berkshire, England, 2000. 450 p.

Zinke, P.J. Forest interception studies in the United States. In: Sopper, W.E. e Lull, H.W. eds. International Symposium on Forest Hydrology. New York. Pergamon Press. p. 137-161. 1967.

Enviado para publicação em junho de 2010.

Aceito para publicação em julho de 2010. 